Tropical Journal of Pharmaceutical Research December 2016; 15 (12): 2611-2618

ISSN: $1596-5996$ (print); 1596-9827 (electronic)

(c) Pharmacotherapy Group, Faculty of Pharmacy, University of Benin, Benin City, 300001 Nigeria.

All rights reserved.

Available online at http://www.tjpr.org

Original Research Article

http://dx.doi.org/10.4314/tjpr.v15i12.11

\title{
Evaluation of neuroprotective properties of two synthetic prenylated xanthone analogues against paraquat and 6- hydroxydopamine toxicity in human neuroblastoma $\mathrm{SH}$ - SY5Y cells
}

\author{
Alan Koh-Siong Nga ${ }^{1}$, Lai-Yeng Tho ${ }^{2}$, Cheng-Hoe Lim $^{2}$, Chan-Kiang Lim $^{2}$ and \\ Yee-How Say ${ }^{1 *}$ \\ ${ }^{1}$ Department of Biomedical Science, ${ }^{2}$ Department of Chemical Science, Faculty of Science, Universiti Tunku Abdul Rahman \\ (UTAR) Kampar Campus, Kampar, Perak, Malaysia
}

*For correspondence: Email: sayyh@utar.edu.my; Tel: +605-4688888 ext 4505; Fax: +605-4661676

Received: 26 August 2016

Revised accepted: 19 November 2016

\begin{abstract}
Purpose: To investigate whether two synthetic prenylated xanthone analogues - 1,3,6,8-tetrahydroxy9H-xanthen-9-one (SX1) and 1,3,6-trihydroxy-2-(3-methylbut-2-enyl)-9H-xanthen-9-one (SX2) - are potential candidates for neuroprotection against paraquat- and 6-hydroxydopamine (OHDA)-induced human neuroblastoma SH-SY5Y cell death.

Methods: SH-SY5Y cells were treated with SX1 and SX2, and the maximum non-toxic dose (MNTD) were obtained by 3-(4,5-dimethylthiazol-2-yl)-2,5-diphenyltetrazolium bromide (MTT) assay. MTT assay was also used to assess the ability of MNTD and half MNTD (HMNTD) doses of SX1 and SX2 to protect against the neurotoxicity of $200 \mu \mathrm{M}$ paraquat and $100 \mu \mathrm{M}$ 6-OHDA. Intracellular ROS production by SHSY5Y cells treated or untreated with SX1 or SX2 was measured by dichloro-dihydro-fluorescein diacetate (DCFH-DA) assay.

Results: SX1 and SX2 MNTDs at concentrations of $1850 \mathrm{nM}$ and $105 \mathrm{nM}$, respectively, did not significantly $(p>0.05)$ provide neuroprotection against paraquat-induced SH-SY5Y cell death. Only SX2 MNTD and HMNTD significantly $(p<0.05)$ protected SH-SH5Y cells against $6-O H D A$-induced cell death by 10 and $17 \%$ improved cell viability. Although intracellular ROS production was significantly attenuated by SX1 HMNTD and MNTD, this did not improve cell viability against paraquat-induced cell death.

Conclusion: These results reveal that SX2 confers neuroprotection on 6-OHDA-induced SH-SY5Y neurotoxicity. Further investigations to elucidate the detailed molecular mechanisms of neuroprotection by SX2 are warranted.
\end{abstract}

Keywords: Prenylation, Xanthone derivatives, Neuroprotection, Paraquat, Dopamine, Neurotoxicity, Human neuroblastoma SH-SY5Y cell, 6-Hydroxydopamine

Tropical Journal of Pharmaceutical Research is indexed by Science Citation Index (SciSearch), Scopus, International Pharmaceutical Abstract, Chemical Abstracts, Embase, Index Copernicus, EBSCO, African Index Medicus, JournalSeek, Journal Citation Reports/Science Edition, Directory of Open Access Journals (DOAJ), African Journal Online, Bioline International, Open-J-Gate and Pharmacy Abstracts

\section{INTRODUCTION}

Paraquat and 6-hydroxydopamine (6-OHDA) have been used in the laboratory as prototypical neurotoxins to induce neurodegeneration in both in vivo and in vitro settings. 6-OHDA induces neurotoxicity by producing hydrogen peroxide, superoxide radical, oxidized glutathione and hydroxyl radical during its autoxidation [1]. These oxidative stresses may ultimately result in 
neurodegeneration by inducing inflammation of neurons and death of neurons in the brain [2]. Paraquat has been considered as a possible etiologic factor in Parkinson's disease. Divalent paraquat ion $\left(\mathrm{PQ}^{2+}\right)$ in brain is reduced to monovalent paraquat ion $\left(\mathrm{PQ}^{+}\right)$by extracellular enzymes such as NADPH-oxidase in microglia, which then serves as a dopamine transporter substrate [3]. Subsequently, $\mathrm{PQ}^{+}$accumulates in dopaminergic neurons and reestablishes a new redox reaction intracellularly, leading to the generation of intracellular free radicals such as superoxide and dopamine reactive substances. This will eventually lead to dopaminergic neuron cell death as seen in Parkinson's disease [3].

Several phytochemicals including fatty acids, phenols, flavonoids, saponins, xanthones and terpenes found in natural products are potential neuroprotective compounds due to their antioxidation and anti-lipid peroxidation activities [4]. Natural or synthetic xanthones, in view of their unique structural chromophore, have been reported to exhibit a wide range of biological properties including cytotoxicity, antiinflammatory, antioxidant, antimalarial, antibacterial and antifungal activities [5]. Our previous studies showed that certain synthetic triand tetra-oxygenated prenylated xanthones had cytotoxic activities against cervical and breast cancer cell lines $[6,7]$. A recent finding showed that six newly isolated prenylated xanthones from ethyl acetate soluble extract of Cudrania tricusidata root bark together with six previously identified prenylated xanthones had neuroprotective effects against 6-OHDA-induced cell death in human neuroblastoma SH-SY5Y cells [8]. This provides an early finding that prenylated xanthones could have neuroprotective property against certain drugs or chemicals that induce neurodegeneration like paraquat and 6OHDA.

Therefore, the objective of this study was to evaluate the neuroprotective property of two selected synthetic prenylated xanthone analogues from our previous studies [6,7], against the toxicities of paraquat and 6hydroxydopamine in a dopaminergic cell line human neuroblastoma SH-SY5Y cells.

\section{EXPERIMENTAL}

\section{Prenylated xanthones}

Two selected prenylated xanthone analogues were from our previous studies 1,3,6-trihydroxy$9 \mathrm{H}$-xanthen-9-one (SX1) is compound 1 in [6] and 1,3,6-trihydroxy-2-(3-methylbut-2-enyl)-9Hxanthen-9-one (SX2) is compound 8 in [7]. The structures are shown in Figure 1 and the synthesis processes were as outlined in our previous studies $[6,7]$. These compounds were selected as they have $\mathrm{IC}_{50}$ of $>60 \mu \mathrm{M}$ in human breast cancer MDA-MB-231 cell line [6,7]. A higher $I C_{50}$ of a compound would enable a wider range of dosages to be tested on SH-SY5Y during the determination of Maximum Non-toxic Dose (MNTD).

\section{Cell culture}

Human neuroblastoma SH-SY5Y (ATCC $®$ CRL$2266^{\mathrm{TM}}$ ) was obtained from the American Type Culture Collection (Manassas, VA, U.S.A.). The cells were maintained in Dulbecco's Modified Eagle's Medium (DMEM; Thermo Fischer Scientific PA, USA) containing $10 \%$ Fetal Bovine Serum (FBS; Sigma-Aldrich, MO, USA) and $1 \%$ penicillin-streptomycin (Nacalai Tesque, Japan) by incubating at $37{ }^{\circ} \mathrm{C}$ in a $5 \%(\mathrm{v} / \mathrm{v}) \quad \mathrm{CO}_{2}$ humidified incubator.<smiles>O=c1c2c(O)cc(O)cc2oc2cc(O)cc(O)c12</smiles>

1,3,6,8-tetrahydroxy-9H-xanthen-9-one<smiles>CC(C)=CCc1c(O)cc2oc3cc(O)ccc3c(=O)c2c1O</smiles>

1,3,6-trihydroxy-2-(3-methylbut -2-enyl)-9H-xanthen-9-one

$$
\text { SX1; } 260 \mathrm{~g} / \mathrm{mol}
$$$$
\text { SX2; } 312 \mathrm{~g} / \mathrm{mol}
$$

Figure 1: Structures and molecular weights of two selected prenylated xanthone analogues used in this study. Their codes and molecular weight $(\mathrm{g} / \mathrm{mol})$ are as indicated 


\section{Determination of maximum non-toxic dose (MNTD) by MTT assay and treatment paradigm}

SH-SY5Y human neuroblastoma cells were seeded in 96-well plates at a cell density of 8,000 cells/well in $100 \mu \mathrm{L}$ of complete growth. Upon attachment the next day, the cells were replaced with serum-free medium (basic medium) on next day for another $24 \mathrm{~h}$ to synchronize the growth stage of cells. On the third day, the cells were treated with synthetic prenylated xanthones SX1 and SX2 dissolved in dimethyl sulfoxide (DMSO), at a range of concentrations from 0 to $5000 \mathrm{nM}$ by two-fold dilution, for $48 \mathrm{~h}$.

Cells were then rinsed twice with phosphate buffer saline (PBS) and $20 \mu \mathrm{L}$ of 3-(4,5dimethylthiazol-2-yl)-2.5-diphenyltetrazolium bromide (MTT) reagent (Bio Basic Canada Inc., Canada) stock solution (5 mg/mL) was then added to each well. The cells were then incubated at $37{ }^{\circ} \mathrm{C}$ for $4 \mathrm{~h}$, before $100 \mu \mathrm{L}$ of DMSO was added to solubilize the purple formazan crystals. After an hour of incubation, the absorbance was measured at the wavelength of $570 \mathrm{~nm}$ using a microplate reader (M200 Tecan, Switzerland). To determine the MNTD or $1 / 2$ MNTD of SX1 and SX2, a graph of percentage of toxicity against the $\log 10$ concentration of compounds was plotted. MNTD was determined at the first $\mathrm{x}$-intercept where the toxicity is $0 \%$, while half MNTD (HMNTD) was half of the MNTD selected.

For the determination of neuroprotection against paraquat and 6-OHDA-induced cell death, $\mathrm{SH}$ SY5Y cells were grown at 8,000 cells/well, cultured and starved as mentioned above. On the third day, the cells were incubated with SX1 and SX2 at their MNTDs and HMNTDs for $24 \mathrm{~h}$. On the fourth day, the cells were treated with 200 $\mu \mathrm{M}$ paraquat (stock solution dissolved in filter sterilized deionized water) or $100 \mu \mathrm{M}$ 6-OHDA (stock solution dissolved in filter sterilized deionized water and supplemented with $0.02 \%$ of ascorbic acid and $0.85 \%$ of $\mathrm{NaCl}$ ) in complete growth medium for another $24 \mathrm{~h}$.

MTT assay was then performed as per described above and graphs of percentage cell viability vs. treatments were plotted. Growth control was represented by cells that were cultured with only the medium while the positive control of neuroprotection was represented by the addition of $\mathrm{D}$ - $\alpha$-tocopherol (vitamin $\mathrm{E}$; an antioxidant) during the treatment with paraquat or 6-OHDA.

\section{Determination of intracellular free radical production by dichloro-dihydro-fluorescein diacetate (DCFH-DA) assay}

SH-SY5Y cells were grown at similar density, cultured and starved as mentioned above. On the third day, the medium was removed from each well and cells were rinsed with PBS twice. Then the cells were incubated with $100 \mu \mathrm{M}$ of DCFH-DA (stock solution dissolved in filter sterilized deionized water) in complete growth medium at $37{ }^{\circ} \mathrm{C}$ in $5 \% \mathrm{CO}_{2}$ humidified incubator for $30 \mathrm{~min}$. The growth medium containing DCFH-DA was then removed by pipetting, and the cells were rinsed twice with PBS and incubated with $200 \mu \mathrm{M}$ paraquat or 100 $\mu \mathrm{M}$ 6-OHDA together with the presence or absence of SX1 and SX2 MNTD. Immediately, fluorescence was measured at $485 \mathrm{~nm}$ excitation wavelength and $530 \mathrm{~nm}$ emission wavelength using a microplate reader (M200, Tecan, Switzerland). The readings were taken every 10 min for $30 \mathrm{~min}$ and last reading was taken at 60 min of incubation time. The fluorescence readings were expressed in percentage change in fluorescence intensity compared with wells with media only and without cells.

\section{Statistical analysis}

Data was expressed as mean \pm standard error of the mean (SEM) of at least two independent experiments, which were performed in replicates as stated in the figure legends. Statistical analysis was performed using Student's t-test for comparison between means of two continuous variables using IBM SPSS Statistics software version 16.0 (IBM, NY, USA). A $p$-value of less than 0.05 was considered as statistically significant.

\section{RESULTS}

\section{Maximum non-toxic dose (MNTD) and half maximum non-toxic dose ( $1 / 2$ MNTD)}

Across the range of dosages of SX1 and SX2 tested on SH-SY5Y cells, neurotoxicity ranged from -3 to $7 \%$ (Figure 2); positive values indicate cell death, negative values indicate cell proliferation. Cells treated with SX1 showed more fluctuations in neurotoxicity across the range of dosages tested, while those treated with SX2 showed fluctuations above $0 \%$, starting from $100 \mathrm{nM}$. As determined from the graph, MNTDs of SX1 and SX2 were 1850 and $105 \mathrm{nM}$, respectively, while the HMNTDs were 925 and $52.5 \mathrm{nM}$, respectively. Overall, the MNTD and 
HMNTD of SX1 were observed to be 18-fold higher than SX2.

\section{Neuroprotection against paraquat- and 6- OHDA-induced cell death}

Treatment with paraquat alone significantly induced $21.03 \pm 2.82 \%$ of neurotoxicity on $\mathrm{SH}$ SY5Y cells compared with growth control (Figure $3 \mathrm{~A}$ ), while treatment with 6-OHDA alone induced $13.61 \pm 2.96 \%$ of neurotoxicity (Figure 3B). Coincubation of paraquat with vitamin $E$ (positive control for neuroprotection) significantly increased the viability of SH-SY5Y cells by nearly $20 \%$ as compared with cells treated with paraquat alone (Figure 3A). Similarly, cotreatment of 6-OHDA with vitamin E significantly increased the viability of SH-SY5Y cells by nearly
$18 \%$ as compared with cells treated with 6OHDA alone (Figure 3B). Treatment with MNTDs and HMNTDs of SX1 or SX2 alone did not significantly increase the cell viability compared with the growth control (Figure $3 \mathrm{~A}$ and Figure 3B). Co-incubation of MNTDs and HMNTDs of SX1 or SX2 with paraquat did not significantly protect the cells from neurotoxicity, compared with growth control (Figure 3A). However, cotreatment of MNTDs and HMNTDs of SX2 (but not SX1) with 6-OHDA, significantly increased the cell viability by $11.55 \pm 1.82$ and $17.26 \pm 1.87$ $\%$, respectively, compared with treatment with 6 OHDA alone (Fig 3B). This indicates that SX2, but not $S X 1$, had significant neuroprotection against $6-\mathrm{OHDA}$ neurotoxicity, but not paraquat neurotoxicity.

A.

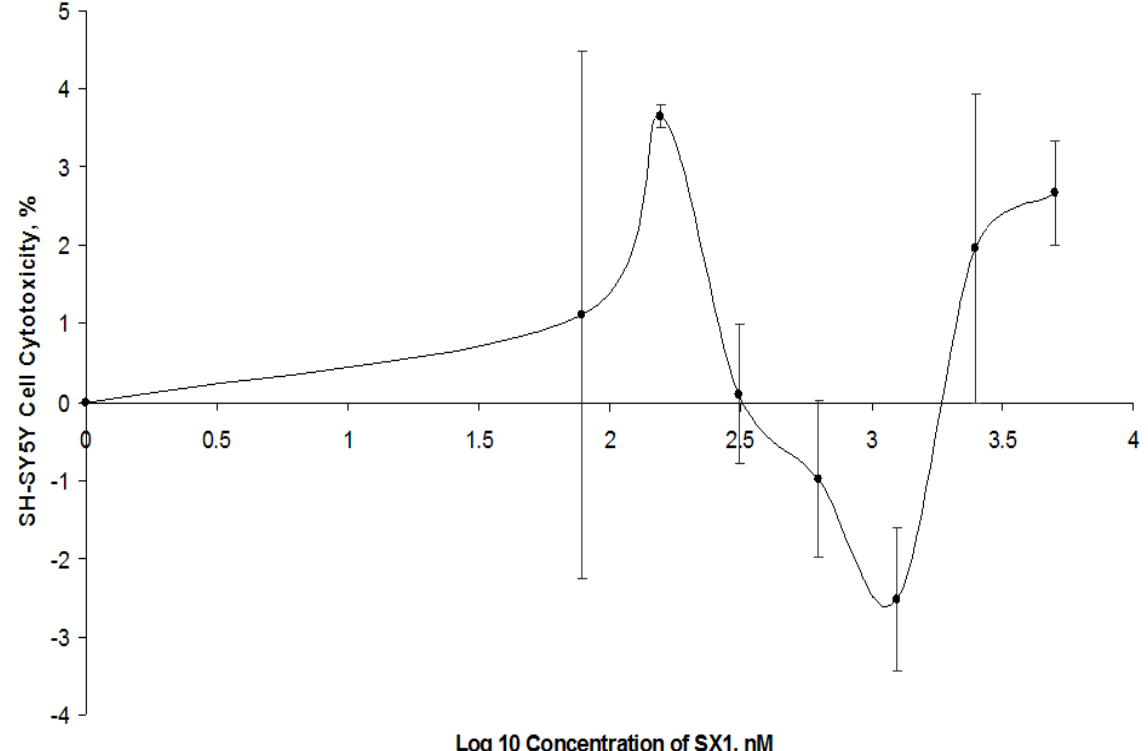

B.

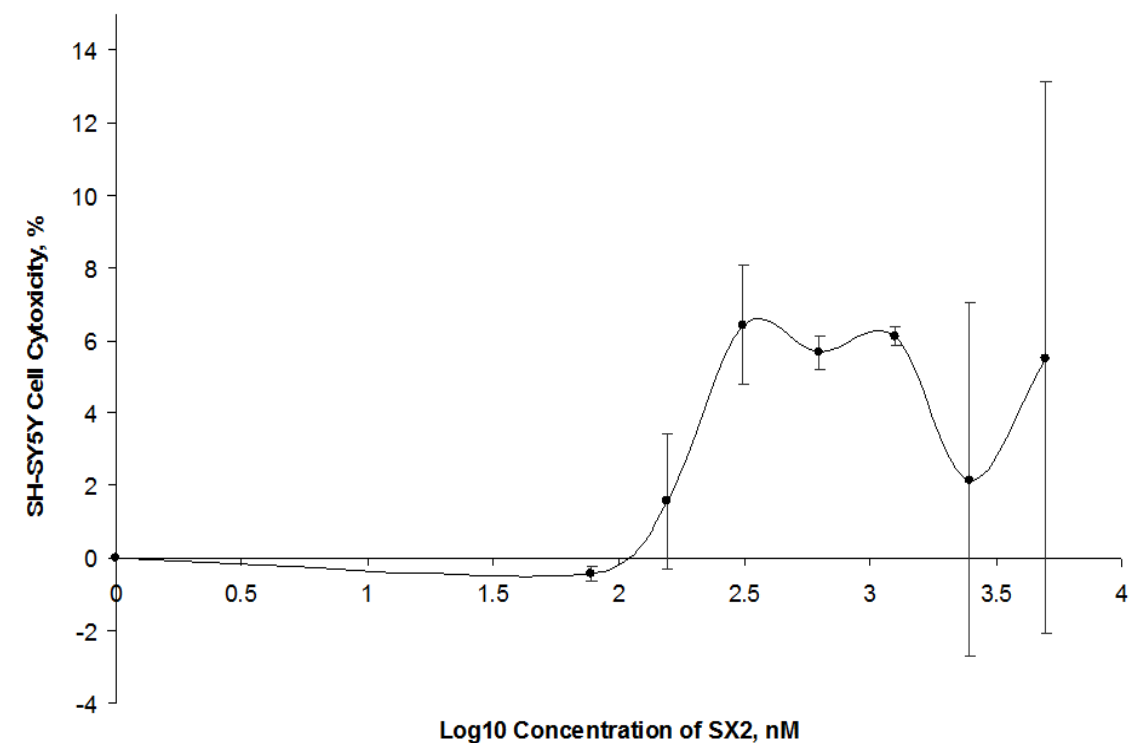

Figure 2: Neurotoxicity of (A) SX1 and (B) SX2 on SH-SY5Y cells after incubation for $48 \mathrm{~h}$, in two fold dilution method with the range of 0 to $5000 \mathrm{nM}$. Data are shown as mean \pm SEM of three independent experiments performed in five replicates 
Intracellular reactive oxygen species (ROS) production by cells treated with paraquat or 6-OHDA

As shown in Fig 4, paraquat treatment alone over $60 \mathrm{~min}$ significantly induced $79.73 \pm 4.09 \%$ increment in intracellular ROS production in $\mathrm{SH}$ SY5Y cells compared with untreated growth control. Addition of vitamin $\mathrm{E}$ (a potent antioxidant) to cells treated with paraquat significantly attenuated the production of intracellular ROS at 20, 30 and $60 \mathrm{~min}$ time points compared with paraquat treatment alone. Intracellular ROS production in cells treated with paraquat and SX1 and SX2 MNTDs and HMNTDs gradually increased across the time points, with SX1 HMNTD showing significances across all time points, compared with paraquat treatment alone (Fig 4).

A.

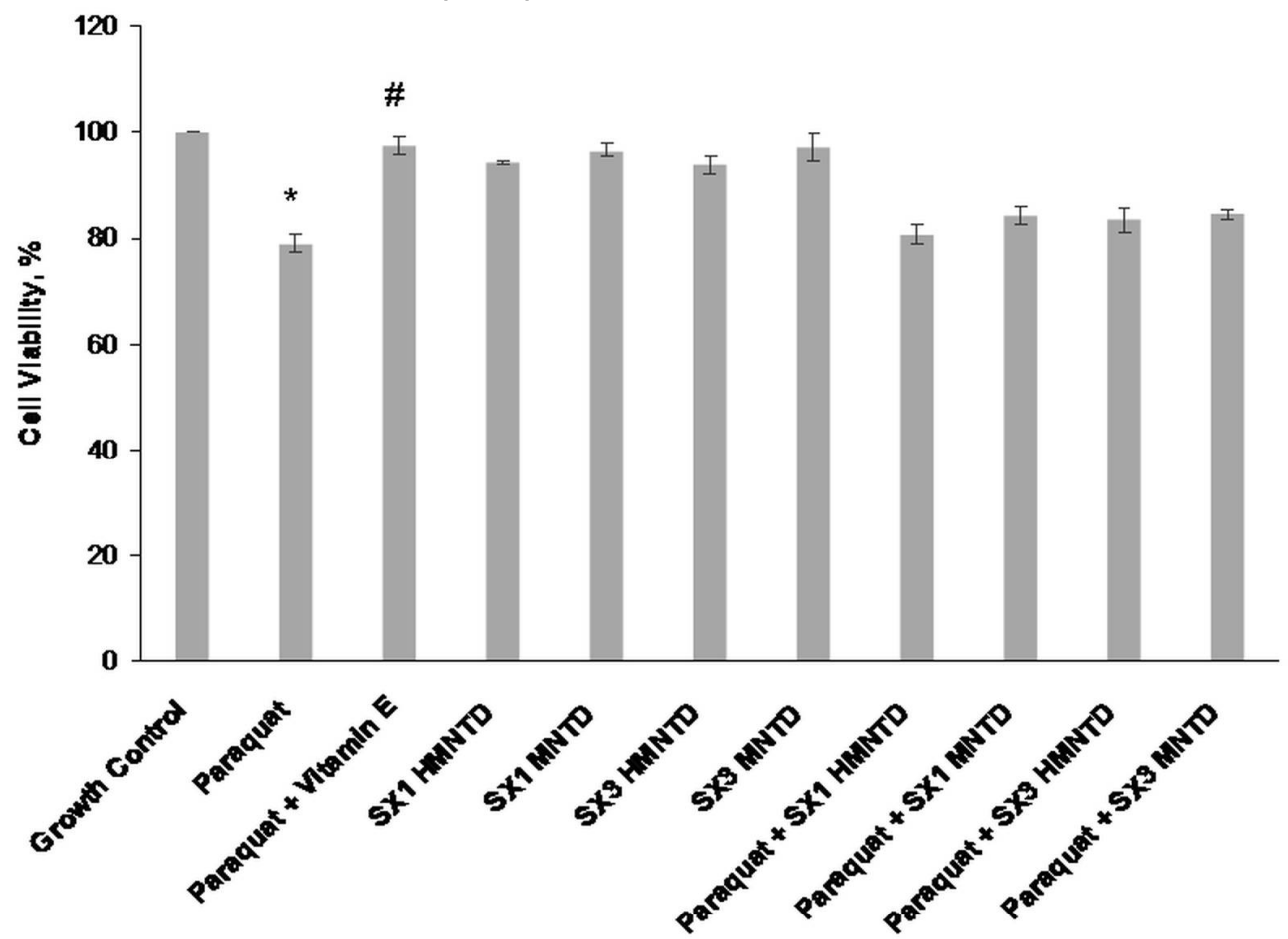

B.

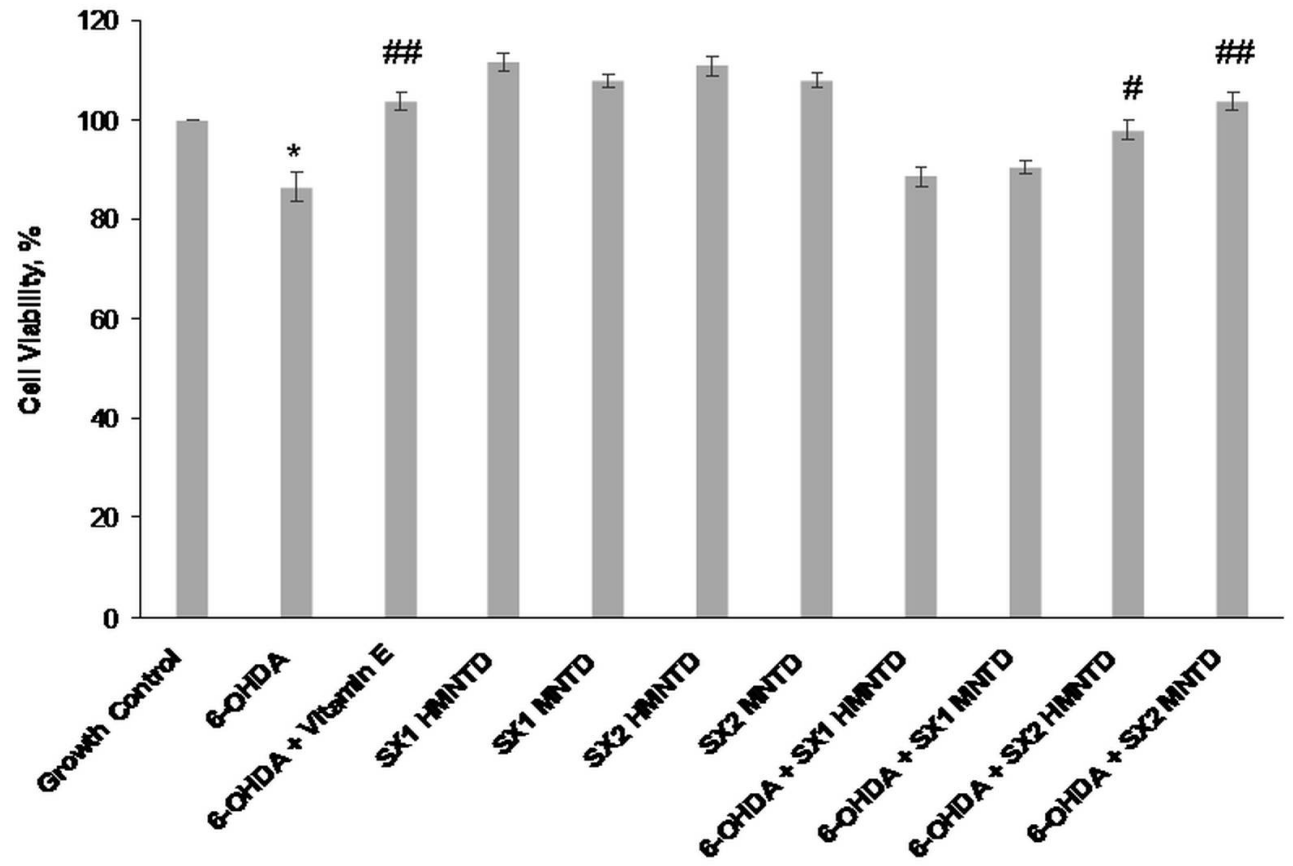

Figure 3: Effect of SX1 and SX2 treatment on paraquat- and 6-OHDA-induced neurotoxicity in SH-5YSY cells. Data are shown as mean \pm SEM of three independent experiments performed in eight replicates; *indicates $p<$ 0.05 compared with growth control while \# indicates $p<0.05$ compared with paraquat or 6 -OHDA treatment alone. 


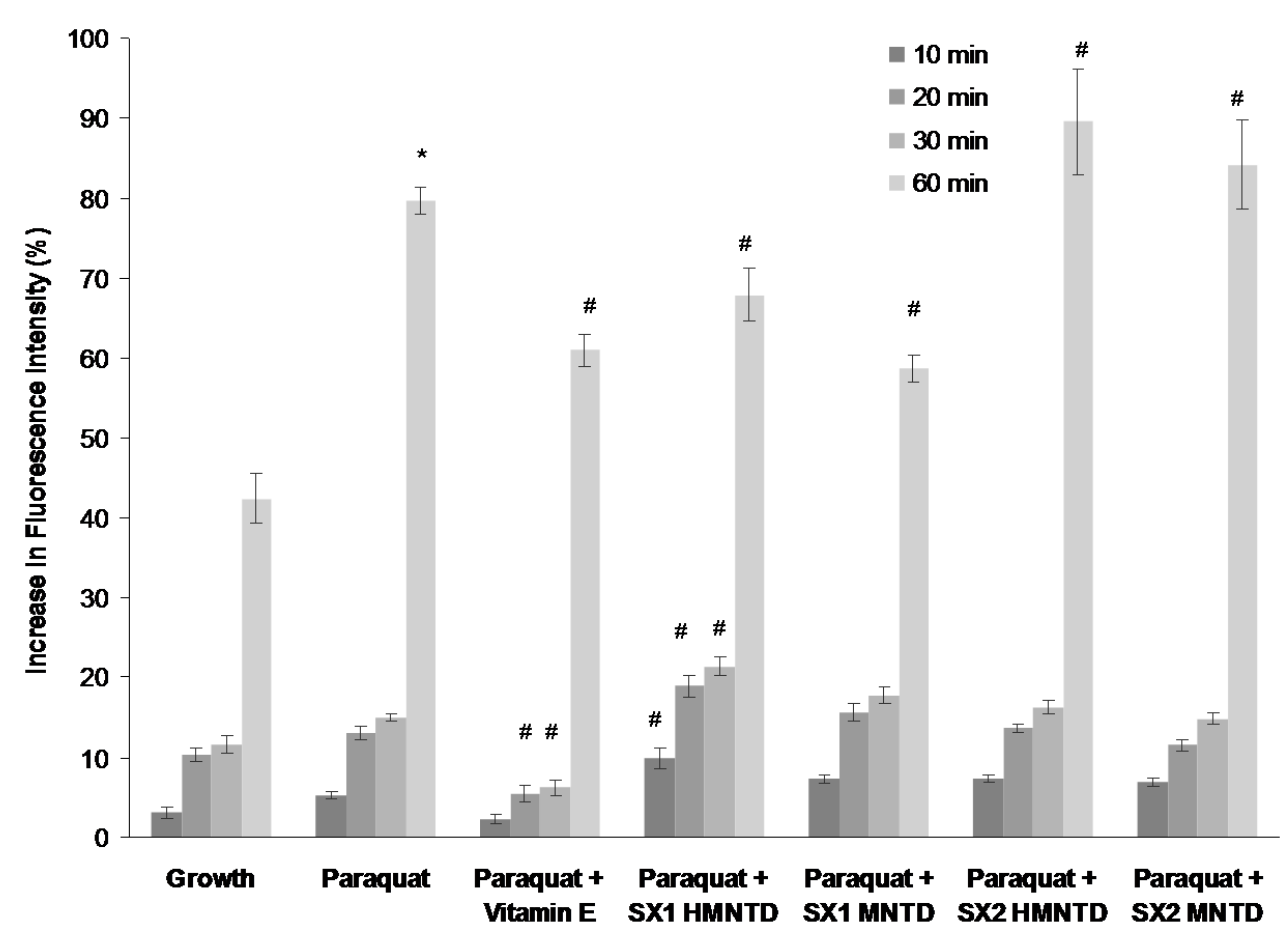

Figure 4: Fluorescence intensity of DCFH-DA upon treatments for $60 \mathrm{~min}$. Data are shown as mean \pm SEM of two independent experiments performed in six replicates; * $p<0.05$ compared with growth control; \#p<0.05 compared with paraquat treatment alone at the same time points; \#\#p<0.01 compared with paraquat or 6-OHDA treatment alone

Addition of SX1 HMNTD significantly increased ROS production at earlier time points $(10,20,30$ min), but significantly attenuated approximately $15 \%$ of intracellular ROS production at $60 \mathrm{~min}$ time point. SX1 MNTD also significantly did so at 60 min. However, treatment with SX2 HMNTD and MNTD significantly increased ROS production at $60 \mathrm{~min}$, instead of decreasing it. The co-treatment of 6-OHDA with SX1 and SX2 HMNTDs and MNTDs produced similar results with the treatment with 6-OHDA alone (data not shown), indicating that SX1 and SX2 did not have any effect in attenuating or increasing intracellular ROS production in SH-SY5Y cells treated with 6-OHDA.

\section{DISCUSSION}

Previously, it was shown that six newly isolated prenylated xanthones from ethyl acetate soluble extract of Cudrania tricusidata root bark (cudratrixanthone C, cudratrixanthone G, cudratrixanthone $\mathrm{H}$, cudratrixanthone $\mathrm{I}$, cudratrixanthone $\mathrm{O}$, 3-O-methylcudratrixanthone $G)$, and six other previously identified prenylated xanthones (cudraxanthone A, 6-deoxyisojacareubin, nigrolineaxanthone $F$, nerifolone $A$, cudraxanthone L, gerontoxanthone $\mathrm{C}$ ), protected against 6-OHDA-induced cell death in human neuroblastoma SH-SH-SY5Y cells [8]. These compounds gave the $\mathrm{EC}_{50}$ values of $0.7-16.6$ $\mu \mathrm{M}$, compared with positive control curcumin $6.0 \mu \mathrm{M}$. In our study, we used a slightly different approach in determining the neuroprotective property of two selected prenylated xanthones 1,3,6-trihydroxy-9H-xanthen-9-one (SX1) and 1,3,6-trihydroxy-2-(3-methylbut-2-enyl)-9Hxanthen-9-one (SX2). We determined their HMNTDs and MNTDs first before these dosages were used to test for potential neuroprotection against paraquat and 6-ODHA-induced neuronal cell death. Determination of MNTD is crucial prior to subsequent neuroprotection assay so that the compound would not pose any neurotoxicity during treatment. This similar approach of MNTD determination first has been used in numerous neuroprotection assays of natural products, such as orientin [9] and edible bird nest (EBN) extract [10].

We found that the neurotoxicity of SX2 was twofold more than the neurotoxicity of SX1, while the MNTD of SX1 was nearly 17 times higher than MNTD of SX2. Orientin, a flavonoid-like phytochemical which showed neuroprotection against oxidative stress-induced $\mathrm{SH}-\mathrm{SY} 5 \mathrm{Y}$ cell death, had MNTD of $20 \mu \mathrm{M}$, which was much 
higher than the MNTDs of SX1 and SX2 [9]. This discrepancy of toxicity profile of SX1 and SX2 is also evident in our previous studies, whereby the inhibitory concentration $\left(\mathrm{IC}_{50}\right)$ of $\mathrm{SX} 1$ on HeLa and MDA-MB-231 were $>60 \mu \mathrm{M}$ and $>60 \mu \mathrm{M}$, respectively [6], while $\mathrm{IC}_{50}$ of SX2 on HeLa and MDA-MB-231 were $48 \mu \mathrm{M}$ and > $60 \mu \mathrm{M}$, respectively [7]. These differences in neurotoxicity profile of $S X 1$ and SX2 could be due to the different mode of action by distinct degree of prenylation of xanthone [11].

Paraquat at $200 \mu \mathrm{M}$ induced nearly $20 \%$ of SHSY5Y neuronal cell death over $24 \mathrm{~h}$ of incubation, consistent with the results of a previous study [12]. Paraquat-induced cell death is possibly caused by the oxidative stress generated during incubation. Specifically, new redox reaction between paraquat radical and oxygen generate true reactive oxygen species, $\mathrm{O}^{2-}$ and $\mathrm{H}_{2} \mathrm{O}_{2}$, which significantly cause cell death $[12,13]$. However, 6-OHDA treatment caused only around $20 \%$ of neuronal cell death compared to $\geq 50 \%$ at similar concentration, as shown in previous studies [14,15]. 6-OHDA is prone to oxidation. Therefore, a prolonged incubation period of $24 \mathrm{~h}$ might have caused the $6-$ OHDA to be oxidized and degraded, rendering it to be no longer a bioactive neurotoxin [16].

Vitamin $\mathrm{E}$ as a lipophilic antioxidant attenuated paraquat and 6-OHDA-induced cell death to nearly $20 \%$ of improved cell viability in SH-SY5Y cells, suggesting that lipid peroxidation plays a role in 6-OHDA and paraquat toxicity [17]. The co-incubation of paraquat with SX1 and SX2 HMNTDs and MNTDs did not significantly protect the cells against paraquat-induced neurotoxicity. In contrast, SX2 HMNTD and MNTD improved cell viability of 6-OHDA challenged SH-SY5Y cells. The majority of xanthones isolated in a previous study have relatively higher dose in order to improve cell viability upon introduction of neurotoxins, while only minor group of xanthones with relatively complex prenylation showed more potent neuroprotection at lower dose [8]. This suggests that the SX1 and SX2 are not as potent as natural xanthones isolated from Cudrania tricuspidata as the MNTDs of SX1 and SX2 were too low to provide neuroprotection against paraquat-induced cell death.

Cells treated with paraquat alone had the strongest intracellular ROS production over 60 min of treatment. This shows that neurotoxic paraquat ion $\left(\mathrm{PQ}^{+}\right)$accumulated in dopaminergic neuron to reestablish a new redox reaction intracellularly, leading to generation of intracellular free radicals such as superoxide and dopamine reactive substances in the neuron [3].
The co-incubation of paraquat with vitamin $E$ significantly reduced intracellular ROS production at time point 10,20,30 and 60 minutes as compared to incubation with paraquat alone. A previous study demonstrated in rodent model that vitamin $E$ could strengthen the antioxidative defense system with an increased activity of antioxidative enzymes, including superoxide dismutase (SOD) and glutathione peroxidase (GSH-px) [18].

The co-incubation of paraquat with SX1 HMNTD and MNTD attenuated intracellular ROS production but did not rescue the SH-SY5Y cells from paraquat-induced cell death, while SX2 HMNTD and MNTD maintained increased intracellular ROS production. The attenuation of intracellular ROS would normally rescue the cell from oxidative stress-induced cell death [10]. However, this was not observed in this study. One of the possible reasons is that the direct free radical scavenging did not sufficiently protect early apoptotic cells against neurotoxin-induced cell death. This indicates that there could other mechanisms involved other than direct antioxidation in rescuing paraquat-induced $\mathrm{SH}-\mathrm{SY} 5 \mathrm{Y}$ cell death. This is evident in a previous study, where the effective free radical scavenging activity of EBN extract did not rescue SH-SY5Y cells from oxidative stress-induced cell death [10].

\section{CONCLUSION}

\section{1,3,6-Trihydroxy-2-(3-methylbut-2-enyl)-9H-} xanthen-9-one (SX2) at $105 \mathrm{nM}$ (MNTD) and $52.5 \mathrm{nM}$ (HMNTD) concentrations successfully confer neuroprotection by significantly protecting SH-SY5Y cells against 6-OHDA-induced cell death by improving 10 and $17 \%$ cell viability. Although intracellular ROS production was significantly attenuated by 1,3,6-trihydroxy-9Hxanthen-9-one (SX1) at $1850 \mathrm{nM}$ (MNTD) and $925 \mathrm{nM}$ (HMNTD) concentrations, the radical scavenging activity of the compounds did not significantly protect SH-SY5Y cells against paraquat-induced cell death.

\section{DECLARATIONS}

\section{Acknowledgement}

This work was supported by an undergraduate research project fund in the Department of Biomedical Science, UTAR.

\section{Conflict of Interest}

No conflict of interest associated with this work. 


\section{Contribution of Authors}

The authors declare that this work was done by the authors named in this article and all liabilities pertaining to claims relating to the content of this article will be borne by them. CKL and YHS conceived and designed the study, AKSN, LYT and $\mathrm{CHL}$ collected and analysed the data, AKSN and YHS wrote the manuscript. All authors read and approved the manuscript for publication.

\section{Open Access}

This is an Open Access article that uses a funding model which does not charge readers or their institutions for access and distributed under the terms of the Creative Commons Attribution License (http://creativecommons.org/licenses/by 14.0) and the Budapest Open Access Initiative (http://www.budapestopenaccessinitiative.org/rea d), which permit unrestricted use, distribution, and reproduction in any medium, provided the original work is properly credited.

\section{REFERENCES}

1. Rodriguez-Pallares J, Parga J, Muñoz A, Rey $P$, Guerra $M$, Labandeira-Garcia J. Mechanism of 6hydroxydopamine neurotoxicity: the role of $\mathrm{NADPH}$ oxidase and microglial activation in 6-hydroxydopamineinduced degeneration of dopaminergic neurons. J Neurochem 2007; 103: 145-156.

2. Koprich JB, Reske-Nielsen $C$, Mithal $P$, Isacson $O$. Neuroinflammation mediated by $I L-1 \beta$ increases susceptibility of dopamine neurons to degeneration in an animal model of Parkinson's disease. $J$ Neuroinflammation 2008; 5: 8. doi:10.1186/1742-20945-8

3. Rappold P, Cui M, Chesser A, Tibbett J, Grima J, Duan $L$, Sen N, Javitch J, Tieu K. Paraquat neurotoxicity is mediated by the dopamine transporter and organic cation transporter-3. PNAS USA 2011; 108: 2076620771.

4. Kumar GP, Khanum F. Neuroprotective potential of phytochemicals. Pharmacogn Rev 2012; 6: 81-90.

5. Negi JS, Bisht VK, Singh P, Rawat MSM, Joshi GP. Naturally occurring xanthones: chemistry and biology. J App Chem 2013; 2013: 621459.

6. Lim KC, Tho LY, Lim CH, Lim YM, Shah SAA, Weber JFW. Synthesis and SAR study of prenylated xanthone analogues as HeLa and MDA-MB-231 cancer cell inhibitors. Lett Drug Des Discov 2011; 8: 523-528.

7. Lim KC, Tho LY, Lim YM, Shah SAA, Weber JFW. Synthesis of 1,3,6-trioxygenated prenylated xanthone derivatives as potential antitumor agents. Lett Org Chem 2012; 9: 549-555.

8. Kwon J, Hiep NT, Kim DW, Hwang BY, Lee HJ, Mar W, Lee $D$. Neuroprotective xanthones from the root bark of Cudrania tricuspidata. J Nat Prod 2014; 77: 1893-1901.

9. Law B, Ling $A$, Koh RY, Chye SM, Wong YP. Neuroprotective effects of orientin on hydrogen peroxide induced apoptosis in SH SY5Y cells. Mol Med Rep 2013; 9: 947-954.

10. Yew M, Koh R, Chye SM, Othman I, Ng K. Edible bird's nest ameliorates oxidative stress-induced apoptosis in SH-SY5Y human neuroblastoma cells. BMC Complement Altern Med 2014; 14: 391.

11. Na Y. Recent cancer drug development with xanthone structures. J Pharm Pharmacol 2009; 61: 707-712.

12. Fordel E, Thijs L, Martinet W, Lenjou M, Laufs $T$, Van Bockstaele D, Moens L, Dewilde S. Neuroglobin and cytoglobin overexpression protects human $\mathrm{SH}-\mathrm{SY} 5 \mathrm{Y}$ neuroblastoma cells against oxidative stress-induced cell death. Neurosci Lett 2006; 410: 146-151.

13. Hassan HM. Exacerbation of superoxide radical formation by paraquat. Methods Enzymol 2006; 105: 523-532.

14. Storch A, Kaftan A, Burkhardt K, Schwarz J. 6Hydroxydopamine toxicity towards human SH-SY5Y dopaminergic neuroblastoma cells: independent of mitochondrial energy metabolism. J Neural Transm 2000; 107: 281-293.

15. Kwon SH, Ma SX, Hong SI, Kim SY, Lee SY, Jang CG. Eucommia ulmoides Oliv. bark attenuates 6hydroxydopamine-induced neuronal cell death through inhibition of oxidative stress in SH-SY5Y cells. J Ethnopharmacol 2014; 152: 173-182.

16. Hanrott K, Gudmunsen L, O'Neill MJ, Wonnacott S. 6hydroxydopamine-induced apoptosis is mediated via extracellular auto-oxidation and caspase 3-dependent activation of protein kinase Cdelta. J Biol Chem 2006; 281: 5373-5382.

17. Kumar $R$, Agarwal $A$, Seth $P$. Free radical-generated neurotoxicity of 6-hydroxydopamine. I Neurochem 2002; 64: 1703-1707.

18. Hong J, Kim M, Park M, Kwag O, Lee I, Byun B, Lee S, Lee $K$, Rhee $S$. Effects of vitamin $E$ on oxidative stress and membrane fluidity in brain of streptozotocin-induced diabetic rats. Clin Chim Acta 2004; 340: 107-115. 